\title{
A study on the efficacy and safety of Blonanserin in Indian patients in Ahmedabad: a randomized, active controlled, phase III clinical trial
}

\author{
Bhavesh Lakdawala ${ }^{1}$, Mahemubin S. Lahori ${ }^{2}$, Ganpat K. Vankar ${ }^{3}$ \\ ${ }^{1}$ Associate Professor, Dept. of Psychiatry, AMC-MET Medical College and Sheth L.G. General Hospital, \\ Ahmedabad, Gujarat, India. \\ ${ }^{2}$ Assistant Professor, Dept. of Psychiatry, GMERS Medical College and General Hospital, Sola, Gujarat, \\ India. \\ ${ }^{3}$ Professor, Dept. of Psychiatry, Jawaharlal Nehru Medical College and Acharya Vinoba Bhave Rural \\ Hospital Wardha, Maharashtra \\ Corresponding author: Dr. Mahemubin Lahori \\ Email-mubinr@gmail.com
}

\begin{abstract}
Introduction: Blonanserin is a novel atypical antipsychotic with higher dopamine $\mathrm{D}_{2}$ receptor occupancy and lower serotonin $5-\mathrm{HT}_{2 \mathrm{~A}}$ receptor blocking activity as compared to the other atypical antipsychotics. The objective of this study was to compare the efficacy and safety of blonanserin with haloperidol in Indian patients with schizophrenia.

Methodology: This was an 8 week, randomized, open label, active controlled, multicentre study. Patients diagnosed with schizophrenia according to the DSM-IV criteria were enrolled in the study. Patients were randomized to receive either blonanserin (16 mg/day) or haloperidol ( $4.5 \mathrm{mg} /$ day). Patients were assessed on an out-patient basis after every 2 weeks for clinical efficacy [Positive and Negative Syndrome Scale (PANSS) total and factor scores], Clinical Global Impressions-severity CGI-S, Clinical Global Impressions-Improvement (CGI-I), Global Assessment of Efficacy (CGI-C), adverse events and drug compliance.

Results: At our centre, total 60 patients were randomized in the study with 30 patients each in Blonanserin and Haloperidol group. Both blonanserin and haloperidol were effective in reducing the PANSS score at the end of the study as compared to the baseline $(\mathrm{P}<0.001)$. There was a significantly more decline in the mean total PANSS score from $78.5 \pm 15.6$ (range: $43-105$ ) at baseline (Week 0) to $35.0 \pm 8.8$ (range: 14-54) at last assessment (Week 8) in the patients enrolled in Study Arm of Blonanserin; as compared to decline in the same from $67.7 \pm 14.0$ (range: 39-93) at baseline (Week 0) to $31.0 \pm 5.7$ (range: 21-43) at last assessment (Week 8) in Study Arm of Haloperidol. Blonanserin was superior to Haloperidol in control of negative symptoms of schizophrenia. On Clinical Global Impression for change in disease severity (CGIS) at the end of treatment period; 10 (35.7\%) patients had "much improvement" in Blonanserin group. On the other hand, $5(17.2 \%)$ patients had "much improvement" in Haloperidol group. Blonanserin was well tolerated by the patients with the most common adverse event being extrapyramidal symptoms.

Conclusion: Blonanserin was found to be non-inferior to haloperidol in the treatment of patients with schizophrenia and was superior to haloperidol for the treatment of negative symptoms of schizophrenia. Blonanserin has a great potential to be a new atypical first line drug for the treatment of schizophrenia.
\end{abstract}

Key Words: Blonanserin, Haloperidol, India, Schizophrenia, Atypical antipsychotics

(Paper received $-11^{\text {th }}$ November 2017, Peer review completed $-25^{\text {th }}$ November 2017)

(Accepted $-28^{\text {th }}$ November 2017)

(Clinical Trials Registry of India: CTRI/2011/091/000140) 


\section{INTRODUCTION}

Schizophrenia is a complex heterogeneous psychiatric disorder with diverse manifestations including positive (e.g. hallucinations, delusions, agitations), negative (e.g. affective flattening, anhedonia, avolition, alogia) and disorganised (e.g. disorganised behaviour and speech, poor attention) symptoms; mood symptoms (e.g. depression) and cognitive impairments [1]. It affects about 7 per thousand of the adult population, mostly in the age group of 15-35 years, impairing their personal, social and occupational functioning [2].

Antipsychotic pharmacotherapy is the mainstay for the treatment of schizophrenia. Typical antipsychotics like haloperidol are effective in controlling the positive symptoms but have little effect on the negative symptoms and are often associated with severe adverse events like extrapyramidal symptoms (EPS) [1]. The development of atypical antipsychotics (e.g. risperidone, olanzapine and clozapine) has led to better control of negative symptoms with lesser propensity of inducing EPS. The enhanced efficacy and reduced adverse events of these atypical antipsychotics are thought to be due to their broader receptor binding profile including seroternegic, adrenergic and muscarinic receptors and weaker antidopaminergic activity [3]. Although the atypical antipsychotics are better than the first generation antipsychotics in the management of schizophrenia, they themselves are accompanied by adverse effects such as metabolic disturbances, weight gain and hyper-prolactinaemia [4]. Moreover, some patients are still only partially responsive to the treatment. Thus, there is a need for atypical agents with both good efficacy and improved tolerability [5].

Blonanserin is a novel atypical antipsychotic with a unique pharmacological receptor profile. It has higher dopamine $\mathrm{D}_{2}$ receptor occupancy and lower serotonin 5- $\mathrm{HT}_{2 \mathrm{~A}}$ receptor blocking activity as compared to the other atypical antipsychotics and is often called as "dopamine-serotonin antagonist". It has lower affinity for serotonin $5-\mathrm{HT}_{2 \mathrm{C}}$ and adrenergic $\alpha_{2}$ receptors while it is almost devoid of histamine $\mathrm{H}_{1}$ and muscarinic $\mathrm{M}_{1}$ antagonistic activity. This selective receptor binding profile of blonanserin may minimize adverse events seen with other atypical antipsychotics. Moreover, blonanserin may have better effect on cognitive function due to its relatively high affinity for $5-\mathrm{HT}_{6}$ receptors [6-8].

The efficacy and safety of blonanserin in the treatment of both positive and negative symptoms of schizophrenia has been demonstrated in various short term (upto 8 weeks) and long term (upto 6 years follow up) clinical studies in comparison to placebo and active comparators like risperidone and haloperidol [7.9]. However, there is dearth of data on the efficacy and safety of blonanserin in the Indian population. We report the results of a randomized, multicentre study comparing the efficacy and safety of blonanserin with that of haloperidol in Indian patients with schizophrenia in one centre of Ahmedabad. The aim of the study was to assess the comparative efficacy and safety of Blonanserin and Haloperidol in Indian patients with schizophrenia.

\section{METHODOLOGY}

The study was started after approval by the Licencing Authority (Drugs Controller General of India) and the Institutional Ethics Committees of the centre. Study was conducted at B.J. Medical College and New Civil Hospital, Ahmedabad. It was conducted in compliance with the Good Clinical Practise Guidelines, the local regulatory requirements and the ethical principles of the Declaration of Helsinki. The study was registered on Clinical Trials Registry of India (CTRI/2011/091/000140). Written informed consent was obtained from all the patients before enrolment in the study.

Patients of either sex, 18 to 65 years of age and diagnosed with schizophrenia according to the Diagnostic and Statistical Manual of Mental Disorders, Fourth Edition (DSM-IV) ${ }^{[10]}$ were enrolled in the study. Patients were excluded from the study if they had history of any organic psychiatric disorder, lack of response to antipsychotic treatment, any other psychiatric or neurological illness or neuroleptic malignant syndrome. Patients with other clinically significant illnesses (e.g. uncontrolled diabetes, significant cardiovascular diseases, angle-closure glaucoma, benign prostatic hyperplasia, urinary retention or paralytic ileus, renal or hepatic impairment, malnutrition, dehydration, malignancy), hypersensitive to 
haloperidol or other antipsychotic agents and those judged by the investigator to be at a serious suicidal risk were also excluded. Patients with a history of alcohol or drug abuse and those who had been a part of any other clinical trial in the last three months were not considered for enrollment. Women of child bearing age willing to take part in the study were required to be non-pregnant and use effective contraception during the entire study period.

\section{Study Design}

This prospective, open label, active controlled, multicenter phase III clinical trial was conducted at four different centres in India. This article presents findings of only one centre at Ahmedabad. The study duration was March 2011 to September 2011. Patients enrolled in this 8 week study were randomized to receive either blonanserin or haloperidol. Patients in the blonanserin group (Group B) received blonanserin in a dose of $4 \mathrm{mg}$ twice daily for the first 2 weeks and then $8 \mathrm{mg}$ twice daily for the next 6 weeks. Patients were asked to take blonanserin after meals. Patients enrolled in the haloperidol group (Group H) received haloperidol in a dose of $1.5 \mathrm{mg}$ three times a day with or without meals for the entire period of 8 weeks of the study.

During the study period, efficacy, safety and compliance were assessed after every two weeks on an outpatient basis. Compliance was measured by counting the number of tablets returned by the patient at each scheduled visit. Randomization was performed using a centralized computer generated schedule and each patient was given a unique identification number. Patients enrolled in the study were not allowed to receive other antipsychotic agents or drugs known to have pharmacokinetic or pharmacodynamic interactions with the study drugs. Patients were allowed to receive central anticholinergics for the treatment of extra pyramidal symptoms. Medications for other concomitant illnesses, if present, were permitted as deemed necessary by the investigator and recorded in the case report form.

\section{Efficacy and safety assessments}

Efficacy assessment was based on Positive and Negative Syndrome Scale (PANSS) [11] score recorded at baseline and every visit thereafter at interval of 2 weeks. The primary efficacy end point was the mean change in the PANSS total score at the end of the study (Week 8) as compared to the baseline (Week 0). The secondary efficacy variables were the change in mean PANSS factor scores (positive and negative) at the end of study as compared to baseline, change in PANSS total and factor scores at each visit as compared to baseline and change in Clinical Global Impressions-severity(CGI-S) and improvement (CGII) assessment scores [12].

Adverse events were documented by the investigators on each visit, including date of onset and end (duration), intensity (mild, moderate or severe), treatment required and outcome. The relationship of the study medication to adverse event was determined by the WHO-UMC (World Health Organization Uppsala Monitoring Centre) [13] criteria for each adverse event. Standard laboratory tests including haematology, and blood biochemistries were performed before administration of the study drug and at the end of the treatment for the assessment of safety of the study medications. Clinically significant abnormalities in the laboratory investigations were documented as adverse events.

\section{STATISTICAL ANALYSIS}

All the analysis of primary and secondary efficacy variables were performed on the modified intention-totreat (mITT) population, which was defined as all the randomized patients who met the inclusion / exclusion criteria, received the study medication and had the efficacy information recorded at baseline and at the end of four weeks of treatment. The safety population comprised of all the randomized patients who took at least one dose of the study medication and completed at least one post randomization visit. The last observation carried forward (LOCF) approach was used to impute the missing values.

The data collected during the study was analysed for demographics, efficacy and safety. Data are presented as mean \pm SD or mean (95\% Confidence Interval: lower limit, higher limit) or number (proportion). The non-inferiority margin was less than half the difference between the Haloperidol Group and the Blonanserin Group [14]. Blonanserin was considered to be non-inferior to haloperidol for the 
treatment of schizophrenia if the upper limit of the $95 \%$ two sided confidence interval for the difference in the mean change in total PANSS score as compared to the baseline between the two treatments (Group B minus Group H) was less than 7.5 points [15]. Unpaired student T-test and chi-square $(\chi 2)$ test were used for analysis where applicable and $P$ values $<0.05$ were considered to be statistically significant.

\section{Patient Characteristics}

\section{RESULTS}

A total of 60 schizophrenic patients were enrolled in the study with 30 patients in Group B and 30 patients in Group $\mathrm{H}$ at our centre.

At the end of 8 weeks, 28 of the 30 patients enrolled in Group B at our centre completed the study as per the Protocol. Of the remaining 2 patients, one patient was withdrawn from the study (after 3 days) as the patient met pre-specified withdrawal criteria of the Protocol and another patient was lost to follow up after Week $2 \&$ could not be traced despite best efforts. Hence, while 29 patients were analyzed for tolerability, 28 patients were analyzed for efficacy to the study medication in this group.

While, all the 30 patients enrolled in Group $\mathrm{H}$ at our centre completed the study as per the Protocol. However, one patient was excluded from the analysis at the end of study as the patient met pre-specified withdrawal criteria of the Protocol. Hence, 29 patients were analyzed for both tolerability and efficacy to the study medication in this group.

Amongst the patients enrolled in the study, 28 patients from Group B and 29 patients from Group H were considered for mITT efficacy analysis. The mITT safety population included 29 patients from Group B and 29 patients from Group $\mathrm{H}$. The patients randomized in the two groups were comparable in terms of age, sex distribution, weight and height. Overall, the patients had a similar disease severity at baseline as judged by the duration of illness, PANSS scores and CGI-S scores.

\section{Demographic Data}

All the patients enrolled into the study at our centre were suffering from schizophrenia with the mean duration of illness of 7.2 \pm 4.6 years (range: $0.6-15$ years) in Study Group B and $6.1 \pm 4.9$ years (range: $0.6-16$ years) in Study Group H.

\section{Study Group B (Blonanserin tablets)}

Majority of patients (18 of the 29 patients i.e., 62.1\%) enrolled in this group at our centre were males. The mean age of the patients enrolled in this arm was $37.8 \pm 13.3$ years (range: $20-65$ years). The mean height and mean body weight of the patients enrolled in this arm was $159.0 \pm 8.1 \mathrm{~cm}$ (range: $145-172 \mathrm{~cm}$ ) and $53.8 \pm 10.6 \mathrm{~kg}$ (range: $39-88 \mathrm{~kg}$ ) respectively.

\section{Study Group H (Haloperidol tablets)}

Majority of patients (18 of the 29 patients i.e., $62.1 \%$ ) enrolled in this group at our centre were males. The mean age of the patients enrolled in this arm was $39.7 \pm 11.7$ years (range: 18-65 years). The mean height and mean body weight of the patients enrolled in this arm was $157.1 \pm 8.8 \mathrm{~cm}$ (range: $140-172 \mathrm{~cm}$ ) and $51.7 \pm 5.7 \mathrm{~kg}$ (range: $41-62 \mathrm{~kg}$ ) respectively.

\section{Efficacy Data}

\section{Primary efficacy variables}

The primary efficacy variable was the degree of improvement in the PANSS total score at the end of the study (Week 8) as compared to the baseline (Week 0).

There was a significantly more decline in the mean total PANSS score from $78.5 \pm 15.6$ (range: 43-105) at baseline (Week 0) to $35.0 \pm 8.8$ (range: 14-54) at last assessment (Week 8) in the patients enrolled in Study Group B ; as compared to decline in the same from $67.7 \pm 14.0$ (range: $39-93$ ) at baseline (Week 0) to 31.0 \pm 5.7 (range: 21-43) at last assessment (Week 8) in the patients enrolled in Study Group H. Thus a mean reduction in PANSS total score of $43.5 \pm 9.3$ in Study Group B and the same of $36.6 \pm 10.0$ in Study Group $\mathrm{H}$ was reported at the end of treatment as compared to the baseline (Table 1). 


\section{Secondary efficacy variables:}

The degree of improvement in the PANSS factor scores at the end of the study (Week 8) as compared to the baseline (Week 0)

There was significantly more improvement in all the PANSS factor scores in Study Arm A as compared to the improvement in the same in Study Arm B at the end of the study (Week 8) as compared to the baseline (Week 0). Please refer to Table 1 below for the details of change in PANSS factor scores in both the groups.

Table 1 - Mean PANSS factor scores as assessed during the study

\begin{tabular}{|c|c|c|c|c|c|c|c|c|}
\hline $\begin{array}{l}\text { Mean total } \\
\text { score }\end{array}$ & $\begin{array}{l}\text { Stdy } \\
\text { Grp }\end{array}$ & $\begin{array}{c}\text { Visit } 1 \\
\text { (Week 0) }\end{array}$ & $\begin{array}{c}\text { Visit } 2 \\
\text { (Week 2) }\end{array}$ & $\begin{array}{c}\text { Visit } 3 \\
\text { (Week 4) }\end{array}$ & $\begin{array}{c}\text { Visit } 4 \\
\text { (Week 6) }\end{array}$ & $\begin{array}{c}\text { Visit } 5 \\
\text { (Week 8) }\end{array}$ & $\begin{array}{c}\text { Mean } \\
\text { Change* }\end{array}$ & $\begin{array}{c}\mathbf{P} \\
\text { Value* }\end{array}$ \\
\hline \multirow{2}{*}{$\begin{array}{c}\text { Positive } \\
\text { symptoms }\end{array}$} & B & $\begin{array}{c}18.5 \pm 6.0 \\
(6-28)\end{array}$ & $\begin{array}{c}15.9 \pm 4.9 \\
(6-24)\end{array}$ & $\begin{array}{c}13.6 \pm 5.0 \\
(4-23)\end{array}$ & $\begin{array}{c}10.4 \pm 4.1 \\
(4-17)\end{array}$ & $\begin{array}{c}8.0 \pm 3.2 \\
(2-14)\end{array}$ & $10.5 \pm 3.7$ & \multirow{2}{*}{0.19} \\
\hline & $\mathrm{H}$ & $\begin{array}{c}16.4 \pm 5.3 \\
(4-26)\end{array}$ & $\begin{array}{c}14.4 \pm 4.6 \\
(4-21)\end{array}$ & $\begin{array}{c}12.4 \pm 4.2 \\
(3-20)\end{array}$ & $\begin{array}{c}9.4 \pm 3.1 \\
(3-15)\end{array}$ & $\begin{array}{c}7.2 \pm 2.4 \\
(1-11)\end{array}$ & $9.2 \pm 3.5$ & \\
\hline \multirow{2}{*}{$\begin{array}{l}\text { Negative } \\
\text { symptoms }\end{array}$} & B & $\begin{array}{c}20.4 \pm 4.4 \\
(12-34)\end{array}$ & $\begin{array}{c}18.5 \pm 4.7 \\
(11-34)\end{array}$ & $\begin{array}{c}15.6 \pm 4.3 \\
(9-28)\end{array}$ & $\begin{array}{c}12.6 \pm 3.2 \\
(6-21)\end{array}$ & $\begin{array}{c}10.1 \pm 3.1 \\
(5-17)\end{array}$ & $10.3 \pm 2.8$ & \multirow{2}{*}{$0.001^{*}$} \\
\hline & $\mathrm{H}$ & $\begin{array}{c}17.0 \pm 4.0 \\
(6-23)\end{array}$ & $\begin{array}{c}15.4 \pm 4.3 \\
(6-22)\end{array}$ & $\begin{array}{c}13.2 \pm 3.3 \\
(6-18)\end{array}$ & $\begin{array}{c}11.2 \pm 3.3 \\
(4-16)\end{array}$ & $\begin{array}{c}9.1 \pm 2.8 \\
(3-14)\end{array}$ & $7.9 \pm 2.6$ & \\
\hline \multirow{2}{*}{$\begin{array}{c}\text { General } \\
\text { psychopat } \\
\text { hology }\end{array}$} & B & $\begin{array}{c}39.6 \pm 8.5 \\
(20-52)\end{array}$ & $\begin{array}{c}34.0 \pm 7.6 \\
(19-50)\end{array}$ & $\begin{array}{c}28.6 \pm 7.1 \\
(14-40)\end{array}$ & $\begin{array}{c}22.4 \pm 6.1 \\
(9-33)\end{array}$ & $\begin{array}{c}16.8 \pm 4.3 \\
(7-25)\end{array}$ & $22.8 \pm 5.5$ & \multirow{2}{*}{$0.04^{*}$} \\
\hline & $\mathrm{H}$ & $\begin{array}{c}34.2 \pm 7.9 \\
(18-47)\end{array}$ & $\begin{array}{c}28.9 \pm 6.8 \\
(13-41)\end{array}$ & $\begin{array}{c}25.3 \pm 6.1 \\
(11-37)\end{array}$ & $\begin{array}{c}20.0 \pm 5.3 \\
(11-33)\end{array}$ & $\begin{array}{c}14.7 \pm 3.5 \\
(8-24)\end{array}$ & $19.5 \pm 6.3$ & \\
\hline \multirow{2}{*}{$\begin{array}{c}\text { PANSS } \\
\text { Total }\end{array}$} & B & $\begin{array}{c}78.5 \pm 15.6 \\
(43-105)\end{array}$ & $\begin{array}{c}68.4 \pm 14.3 \\
(40-95)\end{array}$ & $\begin{array}{c}57.8 \pm 14.0 \\
(31-82)\end{array}$ & $\begin{array}{c}45.5 \pm 11.4 \\
(20-69)\end{array}$ & $\begin{array}{c}35.0 \pm 8.8 \\
(14-54)\end{array}$ & $43.5 \pm 9.3$ & \multirow{2}{*}{0.009 * } \\
\hline & $\mathrm{H}$ & $\begin{array}{c}67.7 \pm 14.0 \\
(39-93)\end{array}$ & $\begin{array}{c}58.8 \pm 13.1 \\
(26-81)\end{array}$ & $\begin{array}{c}50.9 \pm 11.0 \\
(24-68)\end{array}$ & $\begin{array}{c}40.7 \pm 8.9 \\
(23-54)\end{array}$ & $\begin{array}{c}31.0 \pm 5.7 \\
(21-43)\end{array}$ & $36.6 \pm 10.0$ & \\
\hline
\end{tabular}

The degree of improvement in the PANSS total and PANSS factor scores as assessed on each visit as compared to baseline. As depicted in Table 1 above, there was better improvement in the PANSS total and all the PANSS factor scores in Study Group B as compared to the improvement in the same in Study Group $\mathrm{H}$ as assessed on each visit.

The degree of improvement in the Clinical Global Impressions for disease severity (CGI-S) and improvement assessment scores as assessed on each follow-up visit as compared to baseline

The mean severity score on Clinical Global Impression for disease severity (CGI-S) declined significantly more from $4.2 \pm 0.6$ (range: $3-5$ ) at baseline to $2.9 \pm 0.6$ (range: $2-4$ ) at the end of the study (Week 8) in Study Group B as compared to decline in the same from $3.9 \pm 0.6$ (range: 3-5) at baseline to $2.8 \pm 0.4$ (range: 2-3) at the end of the study (Week 8) in Study Group H. Thus, mean reduction in CGI-S score was $1.4 \pm 0.5$ in Study Group B and $1.1 \pm 0.5$ in Study Group H.

Further, a significantly greater improvement was observed in the patients in Group B on the CGI-I scale at week 8 compared with the patients in Group H (Group B:2.0 \pm 0.8 ; Group H: $2.8 \pm 0.7$; p $<0.001$ ); with $67.0 \%$ of blonanserin-treated patients achieving a CGI-I score $\leq 2$ at week 8 as compared with $32.6 \%$ patients treated with haloperidol $(\mathrm{p}<0.001)$.

\section{Global assessment of efficacy}

On Clinical Global Impression for change in disease severity (CGI-C) at the end of treatment period; 10 (35.7\%) patients had "much improvement" while 18 (64.3\%) patients had "moderate improvement" in Study Group B. On the other hand, 5 (17.2\%) patients had "much improvement", 22 (75.9\%) patients had 
"moderate improvement" and 2 (6.9\%) patients had "minimal improvement" in Study Group H (Global assessment of efficacy: Figure 1)

Figure 1 - Global assessment of efficacy

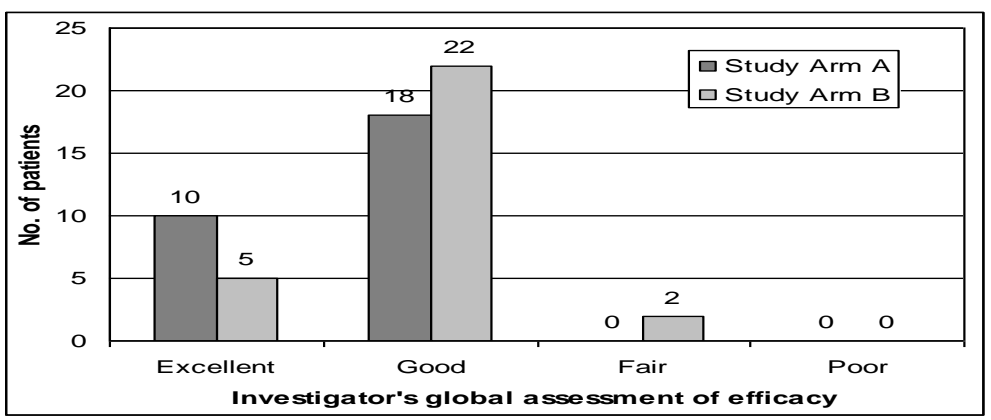

Study Arm A= Blonanserin Group; Study Arm B

\section{Safety and Compliance}

Adverse events in the patients receiving both the drugs were of 'mild' to 'moderate' intensity. The most common adverse event reported by the patients in both the study groups was extrapyramidal symptoms. Other adverse events experienced by the patients in Group B were insomnia, decreased libido and decreased appetite (one patient each) while that in Group H were muscle pain (one patients), anxiety and fatigue (one patient each). But they completed whole study.

Most of the events were rated by the investigators as per the WHO-UMC causality assessment scale. All the adverse events resolved completely, either spontaneously or by symptomatic treatment during the course of the study. Most of the patients experiencing extrapyramidal symptoms were treated with trihexiphenidyl in both the study groups. None of the patients discontinued the study medication due to any adverse event during the entire course of the study. No serious adverse event was reported by any of the patients enrolled in the study. Moreover, there was no clinically significant alteration in any of the routine haematological and biochemical parameters at the end of the therapy with the study drugs as compared to the baseline in any of the patients in this study.

\section{DISCUSSION}

This is the first clinical study to investigate the efficacy and safety of blonanserin for the treatment of patients with schizophrenia in the Indian population. The results of this study indicated that blonanserin was non-inferior to haloperidol in the overall effect on symptoms of schizophrenia (change in total PANSS score) but was superior to haloperidol in the improvement of the negative symptoms of schizophrenia. The drug was well tolerated by the patients with schizophrenia.

With respect to efficacy, blonanserin significantly reduced the total PANSS score from $(78.5 \pm 15.6)$ at baseline to $(35.0 \pm 8.8)$ at the end of the study $(P<0.001)$.The reduction in the PANSS total score was seen as early as two weeks of therapy and was more pronounced and sustained over several weeks of treatment indicating that the efficacy was time dependent. Our study showed the efficacy of blonanserin for a period of 8 weeks only, but various non-comparative clinical trials of upto 56 weeks duration have shown efficacy in the long term treatment of patients with schizophrenia [16-17].

The results of our study showed that the mean change in total PANSS score at end of the study as compared to the baseline with $16 \mathrm{mg} /$ day blonanserin $(43.5 \pm 9.3)$ was not only non inferior but superior to $4.5 \mathrm{mg}$ /day haloperidol $(36.6 \pm 10.0)$. These results are consistent with the previous clinical trials with blonanserin (used in the dose of $8-24 \mathrm{mg} /$ day) which have showed its non-inferiority in the treatment of schizophrenia as compared to the typical antipsychotics like haloperidol (used in the dose of 4-12 $\mathrm{mg}$ /day) and other atypical antipsychotics like risperidone (used in the dose of $2-6 \mathrm{mg} /$ day) $[14,18-20]$. In a previous similar haloperidol-controlled, flexible dose, 8 -week clinical trial no significant difference was 
found between blonanserin ( $8-24 \mathrm{mg} /$ day) and haloperidol (4-12 $\mathrm{mg} /$ day) regarding mean improvements from baseline in PANSS total and positive scores. The non-inferiority was based on final global improvement rate in the trial (62.1\% with blonanserin and $51.3 \%$ with haloperidol) [18].

Although, atypical antipsychotics are generally expected to be better than the typical antipsychotics for the treatment of negative symptoms of schizophrenia, a meta-analysis comparing the typical antipsychotics with the atypical antipsychotics showed that not all the atypical antipsychotics are useful in the treatment of negative symptoms. Drugs like amisulpride, clozapine, olanzapine and risperidone have a greater efficacy than the typical antipsychotics while certain atypical antipsychotics like aripiprazole, quetiapine, sertindole, ziprazidone, and zotepine are not superior to the typical antipsychotics in the treatment of negative symptoms [3]. Sub-score analysis of negative symptoms on PANSS in our study showed a mean change of $10.3 \pm 2.8$ with blonanserin and $7.9 \pm 2.6$ with haloperidol $(\mathrm{p}=0.001)$. A previous metaanalysis $^{[21]}$ of clinical trials of blonanserin showed that the weighted mean difference on PANSS score for control of negative symptoms between blonanserin and haloperidol was -1.29 (95\% CI-2.29, -0.30 ; $P=0.01)$ and between blonanserin and risperidone was $-0.16(95 \%$ CI $-1.00,0.69 ; P=0.72)$. The results from our study are consistent with the results of the meta-analysis showing superiority of blonanserin over haloperidol. Thus, blonanserin is one such atypical antipsychotic with a therapeutic role in treating the negative symptoms in patients with schizophrenia.

Blonanserin was generally well tolerated by the patients enrolled in the study and the adverse event profile was similar to that of haloperidol. Very few patients receiving blonanserin and haloperidol experienced adverse events in our study. Most of the adverse events reported with blonanserin and haloperidol were of 'mild' to 'moderate' intensity. There were no serious adverse events and none of the patients discontinued the study due to adverse events. Previous studies of 8 weeks duration have also shown that the overall tolerability profile of blonanserin is generally similar to that of haloperidol and risperidone [9, 18-19]. Long term treatment with blonanserin for upto 56 weeks was also not associated with any increase in the incidence of adverse events [9]. A recent meta-analysis also did not elicit any difference in the rates of most of the adverse events but showed that blonanserin has a lower risk of hyperprolactinemia as compared to haloperidol and risperidone $(\mathrm{RR}=0.31 ; 95 \% \mathrm{p}<0.00001)$ and lesser risk of dizziness $(\mathrm{RR}$ $=0.47 ; 95 \% \mathrm{CI} 0.23,0.93 ; \mathrm{p}=0.03$, ) and akathisia $(\mathrm{RR}=0.54,95 \% \mathrm{CI} 0.32,0.90 ; \mathrm{p}=0.02)$ as compared to haloperidol [20].

In line with the adverse event profile of blonanserin, recent studies have also shown that it has the highest transitivity to the brain of all the antipsychotics as reflected by the $\mathrm{B} / \mathrm{P}$ ratio (drug concentration in the temporal lobe / drug concentration in the pituitary; blonanserin $=3.88 \pm 5.53$, risperidone $=1.61 \pm 1.00$, haloperidol $=2.40 \pm 2.40$, olanzapine $=2.70 \pm 1.84$, sulpiride $=0.34 \pm 0.42$ ). Higher values indicate that the drug can pass into the brain more easily and will thus have lesser adverse events associated with the dopamine $\mathrm{D}_{2}$ receptor blocking activity in the pituitary like hyperprolactinemia [21-23].

Our study demonstrates the efficacy and safety of blonanserin in patients with schizophrenia at our centre, but it has certain limitations. The efficacy results could be less than optimal in haloperidol group at the dose studied; but an earlier comparative study had also used a similar dose of haloperidol (2-6 mg) in a non-inferiority trial [18]. Moreover, this trial was an open label trial with only 8 weeks treatment duration. Robust clinical trials evaluating the efficacy of blonanserin in patients with first episode of schizophrenia and treatment resistant cases with longer treatment duration and comparison with other atypical antipsychotics would further strengthen the evidence of benefits of blonanserin.

\section{CONCLUSION}

Blonanserin was found to be non-inferior to haloperidol in the treatment of patients with schizophrenia and was superior to haloperidol for the treatment of the negative symptoms of schizophrenia. The drug was well tolerated by the patients. The data from the present clinical trial and published literature suggest that blonanserin has a great potential to be a new atypical first line drug for the short term treatment of schizophrenia and for those requiring longer-term therapy. 


\section{REFERENCES}

1. Kane JM. Schizophrenia. N Engl J Med 1996;334(1):34-41.

2. World Health Organization. Mental disorders - Schizophrenia [Online]. Available from URL: http://www.who.int/mental_health/management/schizophrenia/en/index.html

3. Leucht S, Corves C, Arbter D, Engel RR, Li C, Davis JM. Second-generation versus first-generation antipsychotic drugs for schizophrenia: a meta-analysis. Lancet 2009;373(9657):31-41.

4. Haddad PM, Sharma SG. Adverse effects of atypical antipsychotics: differential risk and clinical implications. CNS Drugs 2007;21(11):911-36

5. Bishara D, Taylor D. Upcoming agents for the treatment of schizophrenia: mechanism of action, efficacy and tolerability. Drugs 2008;68(16):2269-92.

6. Miyamoto S, Duncan GE, Marx CE, Lieberman JA. Treatments for schizophrenia: a critical review of pharmacology and mechanisms of action of antipsychotic drugs. Mol Psychiatry 2005;10:79e104

7. Tenjin T, Miyamoto S, Ninomiya Y, Kitajima R, Ogino S, Miyake N, et al. Profile of blonanserin for the treatment of schizophrenia. Neuropsychiatr Dis Treat 2013;9:587-94

8. Oka M, Noda Y, Ochi Y, et al. Pharmacological profile of AD-5423, a novel antipsychotic with both potent dopamine-D2 and serotonin-S2 antagonist properties. J Pharmacol Exp Ther 1993;264(1):158-65.

9. Deeks ED, Keating GM. Blonanserin: a review of its use in the management of schizophrenia. CNS Drugs 2010;24(1):65-84

10. American Psychiatric Association. Diagnostic and Statistical Manual of Mental Disorders (DSM-IV). Fourth text revision ed. Washington, DC: American Psychiatric Association, 2000

11. Bell M, Milstein R, Beam-Goulet J, Lysaker P, Cicchetti D. The Positive and Negative Syndrome Scale and the Brief Psychiatric Rating Scale. Reliability, comparability, and predictive validity. J Nerv Ment Disease 1992;180(11):723-8.

12. Guy W: ECDEU Assessment Manual for Psychopharmacology -Revised. Rockville, MD, U.S. Department of Health, Education, and Welfare, Public Health Service, Alcohol, Drug Abuse, and Mental Health Administration, NIMH Psychopharmacology Research Branch, Division of Extramural Research Programs, 1976, pp 218-222

13. The use of the WHO-UMC system for standardised case causality assessment[Online]. Available from URL:http://who-umc.org/Graphics/24734.pdf

14. Garcia E, Robert M, Peris F, Nakamura H, Sato N, Terazawa Y. The efficacy and safety of blonanserin compared with haloperidol in acute-phase schizophrenia: a randomized, double-blind, placebo-controlled, multicentre study. CNS Drugs 2009;23:615-25.

15. Hermes ED, Sokoloff D, Stroup TS, Rosenheck RA. Minimum clinically important difference in the Positive and Negative Syndrome Scale with data from the Clinical Antipsychotic Trials of Intervention Effectiveness (CATIE). J Clin Psychiatry 2012;73(4):526-32.

16. Murasaki M. Long-term clinical study of blonanserin for schizophrenia: a multicenter open study to determine safety and effectiveness in schizophrenic patients (Kanagawa Region Clinical Psychopharmacology Study Group) Jpn J Clin Psychopharmacol 2007;10(12):2241-57.

17. Kinoshita T. Long-term clinical study of blonanserin for schizophrenia: a multicenter open study to determine safety and effectiveness in schizophrenic patients (Japan-wide study) Jpn J Clin Psychopharmacol 2008;11(1):135-53.

18. Murasaki M. Clinical evaluation of blonanserin for schizophrenia: a randomized controlled study comparing blonanserin with haloperidol. Jpn J Clin Psychopharmacol 2007;10(11):2059-79.

19. Miura S. Clinical evaluation of blonanserin for schizophrenia: a randomized controlled study comparing blonanserin with risperidone. Jpn J Clin Psychopharmacol 2008;11(2):297-314.

20. Yang J, Bahk WM, Cho HS, et al. Efficacy and tolerability of Blonanserin in the patients with schizophrenia: a randomized, double-blind, risperidone-compared trial. Clin Neuropharmacol 2010;33(4):169-75.

21. Kishi T, Matsuda Y, Nakamura H, Iwata N. Blonanserin for schizophrenia: systematic review and metaanalysis of double-blind, randomized, controlled trials. J Psychiatr Res 2013;47(2):149-54.

22. Arakawa $\mathrm{R}$, Okumura $\mathrm{M}$, Ito $\mathrm{H}$, Takano A, Takahashi $\mathrm{H}$, Takano $\mathrm{H}$, et al. Positron emission tomography measurement of dopamine $\mathrm{D}(2)$ receptor occupancy in the pituitary and cerebral cortex: relation to antipsychotic-induced hyperprolactinemia. J Clin Psychiatry 2010;71:1131-7

23. Tateno A. PET evaluation for dopamine D2 receptor occupancy of blonanserin in schizophrenia patients. Jpn J Clin Psychopharmacol 2011;14:334-41.

Acknowledgements - Department of Psychiatry, B.J. Medical College, Ahmedabad. Conflict of Interest - Nil; Funding - Cadilla Healthcare Ltd., Ahmedabad, India. 